\title{
Relationship between Body Mass Index and Overactive Bladder in Women and Correlations with Urodynamic Evaluation
}

\author{
Tariq F. Al-Shaiji, Sidney B. Radomski \\ Department of Urology, Toronto Western Hospital, Toronto, ON, Canada
}

\begin{abstract}
Purpose: Overactive bladder $(\mathrm{OAB})$ is a common condition. In women, studies have shown that the prevalence of OAB is positively related to increasing body mass index (BMI). Our objective was to define a relationship between BMI and OAB through correlation with urodynamic study (UDS).

Methods: A prospective study was conducted. Ambulatory women aged 18 years or older who had symptoms of OAB for at least 3 months were enrolled. Patients answered a questionnaire, had their weight and height recorded, and underwent UDS. Patients were categorized into 3 groups as follows: group 1, BMI <25; group 2, BMI 25 to 29.9; and group 3, BMI $\geq 30$.

Results: A total of 113 patients were examined (group 1, $n=32$; group 2, $n=40$; group $3, n=41$ ). The patients' mean ages were 50,55 , and 59 years for groups 1,2 , and 3 , respectively $(\mathrm{P}<0.05)$. Group 3 showed a significant increase in the incidence of subjective mixed leakage and the number of pads used compared with groups 1 and 2. No significant differences were seen among the groups in duration of symptoms, OAB V-8 score, or the incidence of subjective urgency or stress leakage. The UDS parameters of groups 1,2, and 3 showed no statistically significant differences for most variables. Group 3 showed a significant increase in the incidence of urge leakage by UDS compared with group 2 only.

Conclusions: Increasing BMI was age related. A BMI $\geq 30$ showed a higher incidence of subjective urinary mixed leakage and pad use. UDS showed no significant correlation between OAB and any BMI category for most UDS parameters.
\end{abstract}

Keywords: Overactive urinary bladder; Body mass index; Urodynamics; Risk factors

\section{INTRODUCTION}

Overactive bladder $(\mathrm{OAB})$ is a common disabling condition that affects health-related quality of life [1]. It has been described as a "syndrome of symptoms" and is defined by the International Continence Society (ICS) as urgency, with or without urge incontinence, usually with frequency and nocturia, in the absence of causative infection or pathological conditions [2,3]. The group of symptoms that constitute $\mathrm{OAB}$ can be interchangeably referred to as lower urinary tract symptoms of an irritative nature. Although several patients with idiopathic $\mathrm{OAB}$ do not show abnormal contractions during urodynamic study (UDS), in the absence of neurological disease, urodynamic findings in $\mathrm{OAB}$ patients can be characterized by the presence of involun- tary bladder contractions that occur during bladder filling despite the patient's attempt to suppress them [4]. The condition is not uncommon, with earlier reports estimating that about one in six adults in the United States and Europe have OAB $[4,5]$.

It has been shown that obesity in adulthood is linked to an increased risk of disability throughout life and a decrease in the length of time spent free of disability [6]. In women, the prevalence of $\mathrm{OAB}$ symptoms has been shown to be positively related to increasing body mass index (BMI) as shown by several authors [7-12]. Nevertheless, all of these studies were epidemiologic in nature and thus provided subjective evidence for such a relationship at best. To our knowledge, published data correlating $\mathrm{BMI}$ and $\mathrm{OAB}$ in women by use of an objective tool are lacking. In a short review from 2000, Cummings and Rodning con-
Corresponding author: Tariq F. Al-Shaiji

Department of Urology, Toronto Western Hospital, University Health Network, South Elevator - Fell Pavilion 8-306, 399 Bathurst St. Toronto, ON, M5T 2S8, Canada

Tel: +1-416-603-5018 / Fax: +1-416-603-1961 / Email: tshaiji@gmail.com

Submitted: June 30, 2012 / Accepted after revision: September 9, 2012
This is an Open Access article distributed under the terms of the Creative Commons Attribution Non-Commercial License (http://creativecommons.org/licenses/by-nc/3.0/) which permits unrestricted non-commercial use, distribution, and reproduction in any medium, provided the original work is properly cited. 
cluded that additional neurophysiologic and UDS results are needed to better define the association between obesity and incontinence [13]. The objectives of this study, therefore, were first to look for any association between $\mathrm{OAB}$ symptoms and BMI in a group of women with $\mathrm{OAB}$ symptoms and second to look for any correlation of BMI with UDS findings in these women.

\section{MATERIALS AND METHODS}

\section{Subjects}

This was a prospective analysis of patients presenting to the clinician's office for consultation regarding $\mathrm{OAB}$ symptoms. The analysis was based on data that were regularly collected when these patients with $\mathrm{OAB}$ presented to our practice and that represent our standard of care. Data collection was kept anonymous.

The inclusion criteria were an ambulatory woman ( $\geq 18$ years of age) with symptoms of $\mathrm{OAB}$ lasting at least 3 months who was able to complete an $\mathrm{OAB}$ questionnaire $(\mathrm{OAB}-\mathrm{q})$ correctly and who had an OAB V-8 score $\geq 8$. Patients were included if they were taking anticholinergics or antispasmodic medication; however, they needed to undergo a minimum 14-day washout period before the UDS.

Exclusion criteria were previous bladder or pelvic surgery, previous incontinence surgery, previous pelvic radiation, clinically significant outflow obstruction, active urinary tract infection, chronic inflammation such as interstitial cystitis and bladder stones, neurological disease (Parkinson's disease, stroke, multiple sclerosis, spinal cord injury), poorly controlled diabetes mellitus, history of bladder or pelvic cancer, previous diagnosis of neurogenic bladder, pregnancy, congestive heart failure, postvoid residual $(\mathrm{PVR})>200$, and excessive fluid intake of $>3 \mathrm{~L}$ per day.

\section{Assessment}

The OAB screen was based on the 8-item OAB Symptom Bother Scale of the OAB-q (V-8), which is a validated questionnaire. Responses were made on a 6-point scale ranging from 0 (not at all) to 5 (a very great deal) for the degree of bother. Patients were considered to have OAB if their OAB V-8 score was $\geq 8$ [14]. During the initial office visit, as per our usual initial consultation, patients provided a medical history, underwent a physical examination, and completed the OAB V-8 questionnaire. On the basis of the initial consultation, some patients underwent UDS (video and nonvideo) and/or cystoscopy. Patients with
$\mathrm{OAB}$ who completed the $\mathrm{V}-8$ questionnaire and underwent UDS were used for the analysis on the basis of the inclusion and exclusion criteria. UDS was performed according to the ICS guidelines [15]. Patients who did not meet the inclusion criteria were excluded. A total of 113 patients underwent UDS. After placement of a 14 Fr two-way Foley catheter (Rusch, Gold), 4 Fr/60 cm bladder pressure catheter (Cook Medical Inc., Bloomington, IN, USA), and $8 \mathrm{Fr} / 107 \mathrm{~cm}$ rectal pressure tube (Tyco Healthcare Kendall, Argyle, NY, USA), the bladder was filled with normal saline or contrast solution at a rate of 25 to $50 \mathrm{~mL} /$ min. The parameters assessed by UDS included storage phase (bladder volume at first desire to void, bladder volume at strong desire to void, maximum cystometric capacity, bladder compliance, detrusor overactivity, detrusor leak point pressure [DLPP], cough stress test, Valsalva leak point pressure [VLPP]) and voiding phases (maximum detrusor pressure, detrusor pressure at maximum flow rate, maximum flow rate, voided volume, PVR, excluding pelvic electromyographic activity). Urethral pressure measurements were not conducted. A Laborie TRITON (Laborie Medical Technologies Co., Mississauga, ON, Canada) multichannel urodynamic system was used for all measurements.

$\mathrm{BMI}$ is a practical and easy index that requires accurate measures of a person's weight and height. It is calculated as weight in kilograms divided by the square of height in meters $\left(\mathrm{kg} / \mathrm{m}^{2}\right)$. All subjects had their weights and heights measured and BMI was calculated at the time of UDS. For the purpose of our analysis, patients were categorized into $3 \mathrm{BMI}$ groups of $<25$ (normal weight), 25 to 29.9 (overweight), and $\geq 30$ (obese). Two patients had a BMI of $<18.5$ corresponding to underweight. These two subjects were included in group 1 (normal weight) because their subjective and objective findings were not significantly different from those of the patients in group 1.

\section{Statistical Analysis}

Chi-square tests were used to evaluate nonparametric data; $\mathrm{z}$ tests and analyses of variance were used to evaluate parametric data. All tests were two-tailed with an alpha of 0.05 . Values are presented as means with ranges.

\section{RESULTS}

Data from a total of 113 patients were examined (group 1, $\mathrm{n}=$ 32 ; group $2, n=40$; group $3, n=41$ ). The patients' mean age was 50 years (range, 24 to 80 years), 55 years (range, 36 to 77 years), 
and 59 years (range, 38 to 80 years) for groups 1, 2, and 3, respectively $(\mathrm{P}<0.05)$, which was a statistically significant difference (Table 1). The majority of the patients' population were anticholenergics naive prior to our study. Only 5 patients were on tolterodine for a short period on presentation that was stopped two weeks prior to the UDS testing (1 patient from group 1, 3 patients from group 2, and 1 patient from group 3).

Subjectively, group 3 showed a statistically significant increase in the incidence of mixed leakage $(\mathrm{P}<0.05)$ and the number of pads used $(\mathrm{P}<0.05)$ when compared with groups 1 and 2 according to the patients' medical history (Tables 2-4). There were no significant differences among the groups in duration of symptoms, OAB V-8 score, or the incidence of urgency or stress leakage on the basis of the patients' medical history (Tables 1-4).

Objectively, the UDS parameters of groups 1,2, and 3 showed no statistically significant differences for most variables, including sensation, compliance, involuntary contractions, pressure amplitude, DLPP, stress leakage, and VLPP (Tables 1-4). However, group 3 showed a significant increase in the incidence of UDS urge leakage $(\mathrm{P}<0.05)$ when compared with group 2 but not group 1 (Tables 3,4 ).

\section{DISCUSSION}

BMI in the range of 25 to 29.9 and $\geq 30$, which corresponds to overweight and obesity, respectively, has been shown to be an

Table 1. Comparison of quantitative data between the three groups $(n=113)$

\begin{tabular}{|c|c|c|c|c|}
\hline Variable & $\begin{array}{c}\text { Group } 1(n=32) \\
\quad(B M I<25)\end{array}$ & $\begin{array}{c}\text { Group } 2(\mathrm{n}=40) \\
(\text { BMI 25-29.9) }\end{array}$ & $\begin{array}{l}\text { Group } 3(n=41) \\
\quad(B M I \geq 30)\end{array}$ & P-value \\
\hline Age (yr) & $49.9(24-80)$ & $55.2(36-77)$ & $58.9(38-80)$ & 0.020 \\
\hline Duration of symptoms (yr) & $4.7(0.25-10)$ & $5.4(0.16-30)$ & $6.5(1-25)$ & 0.20 \\
\hline V-8 overactive bladder score & $22(8-37)$ & $23.1(8-37)$ & $23.7(8-40)$ & 0.94 \\
\hline Highest involuntary contraction pressure $\left(\mathrm{cmH}_{2} \mathrm{O}\right)$ & $33.5(8-130)$ & $26.9(9-79)$ & $42.2(8-92)$ & 0.14 \\
\hline Detrusor leak point pressure $\left(\mathrm{cmH}_{2} \mathrm{O}\right)$ & $34(25-69)$ & $28.5(10-79)$ & $50.7(28-92)$ & 0.073 \\
\hline Valsalva leak point pressure $\left(\mathrm{cmH}_{2} \mathrm{O}\right)$ & $80.2(53-153)$ & $85(47-186)$ & $105.3(37-192)$ & 0.50 \\
\hline
\end{tabular}

Values are presented as mean (range).

BMI, body mass index.

Table 2. Comparison of qualitative data between groups 1 and 2 $(\mathrm{n}=113)$

\begin{tabular}{lccc}
\hline Variable & $\begin{array}{c}\text { Group 1 } \\
(\mathrm{BMI}<25)\end{array}$ & $\begin{array}{c}\text { Group 2 } \\
(\mathrm{BMI} 25-29.9)\end{array}$ & P-value \\
\hline No. out of total & $32(28.3)$ & $40(35.3)$ & 0.5274 \\
Subjective urge leakage only & $7(21.8)$ & $10(25.0)$ & 0.7505 \\
Subjective stress leakage only & $5(15.6)$ & $10(25.0)$ & 0.3291 \\
Subjective mixed leakage & $12(37.5)$ & $14(35.0)$ & 0.8267 \\
Pad use & $16(50.0)$ & $21(52.5)$ & 0.8329 \\
UDS sensation & & & \\
$\quad$ Normal & $21(65.6)$ & $27(67.5)$ & 0.865 \\
Increased & $10(31.2)$ & $7(17.5)$ & 0.1735 \\
Decreased & $1(3.1)$ & $6(15.0)$ & 0.0903 \\
UDS involuntary contractions & $23(71.8)$ & $25(62.5)$ & 0.4054 \\
UDS urge leakage & $12(37.5)$ & $9(22.5)$ & 0.1642 \\
UDS stress leakage & $10(31.2)$ & $14(35.0)$ & 0.7376 \\
\hline
\end{tabular}

Values are presented as number (\%).

BMI, body mass index; UDS, urodynamic study.
Table 3. Comparison of qualitative data between groups 1 and 3 $(\mathrm{n}=113)$

\begin{tabular}{lccc}
\hline Variable & $\begin{array}{c}\text { Group 1 } \\
(\mathrm{BMI}<25)\end{array}$ & $\begin{array}{c}\text { Group 3 } \\
(\mathrm{BMI} \geq 30)\end{array}$ & P-value \\
\hline No. out of total & $32(28.3)$ & $41(36.2)$ & 0.4752 \\
Subjective urge leakage only & $7(21.8)$ & $7(17.0)$ & 0.6045 \\
Subjective stress leakage only & $5(15.6)$ & $4(9.7)$ & 0.4461 \\
Subjective mixed leakage & $12(37.5)$ & $28(68.2)$ & 0.0089 \\
Pad use & $16(50.0)$ & $32(78.0)$ & 0.0124 \\
UDS sensation & & & \\
$\quad$ Normal & $21(65.6)$ & $28(68.2)$ & 0.8142 \\
$\quad$ Increased & $10(31.2)$ & $8(19.5)$ & 0.2497 \\
$\quad$ Decreased & $1(3.1)$ & $5(12.1)$ & 0.1633 \\
UDS involuntary contractions & $23(71.8)$ & $32(78.0)$ & 0.5425 \\
UDS urge leakage & $12(37.5)$ & $20(48.7)$ & 0.3386 \\
UDS stress leakage & $10(31.2)$ & $19(46.3)$ & 0.1922 \\
\hline
\end{tabular}

Values are presented as number (\%).

BMI, body mass index; UDS, urodynamic study. 
Table 4. Comparison of qualitative data between groups 2 and 3 $(\mathrm{n}=113)$

\begin{tabular}{lccc}
\hline Variable & $\begin{array}{c}\text { Group 2 } \\
(\mathrm{BMI} 25-29.9)\end{array}$ & $\begin{array}{c}\text { Group 3 } \\
(\mathrm{BMI} \geq 30)\end{array}$ & P-value \\
\hline No. out of total & $40(35.3)$ & $41(36.2)$ & 0.9331 \\
Subjective urge leakage only & $10(25.0)$ & $7(17.0)$ & 0.3762 \\
Subjective stress leakage only & $10(25.0)$ & $4(9.7)$ & 0.0685 \\
Subjective mixed leakage & $14(35.0)$ & $28(68.2)$ & 0.0028 \\
Pad use & $21(52.5)$ & $32(78.0)$ & 0.0159 \\
UDS sensation & & & \\
Normal & $27(67.5)$ & $28(68.2)$ & 0.9466 \\
Increased & $7(17.5)$ & $8(19.5)$ & 0.8165 \\
Decreased & $6(15.0)$ & $5(12.1)$ & 0.7032 \\
UDS involuntary contractions & $25(62.5)$ & $32(78.0)$ & 0.1268 \\
UDS urge leakage & $9(22.5)$ & $20(48.7)$ & 0.0139 \\
UDS stress leakage & $14(35.0)$ & $19(46.3)$ & 0.3007 \\
\hline
\end{tabular}

Values are presented as number (\%).

BMI, body mass index; UDS, urodynamic study.

independent risk factor for $\mathrm{OAB}$ in women $[6,16]$. The exact mechanisms explaining the link between obesity and $\mathrm{OAB}$ are not well known, however. One hypothesis suggests that excess body weight increases intra-abdominal pressure, which in turn increases bladder pressure and intravesical pressure, thus leading to overactivity $[17,18]$. In theory, increased abdominal pressure "stresses" the muscle, connective tissue, and innervations of the pelvic floor, which may lead to overt structural damage or neurologic dysfunction [19]. One other possible mechanism has been linked to ghrelin - a peptide hormone associated with obesity and metabolism [20]. Tyagi et al. [20] were able to demonstrate the expression of mRNA for the ghrelin receptorgrowth hormone secretagogue receptor (GSHR) - in human bladder. It is hypothesized that the low plasma ghrelin levels observed in obese OAB patients may upregulate the expression of GSHR in the bladder, which may diminish detrusor storage function and lead to OAB [17].

Our study showed that higher BMI was related to increasing age. This agrees with other published results [21,22]. This has been explained secondary to the changes in appetite, food intake, energy expenditure, and body composition that normally occur with aging, with an increase in fat mass and a decrease in muscle mass $[23,24]$.

Of the 113 patients we assessed with OAB, 81 (72\%) fell in the category of high BMI $(\geq 25)$. Although it is premature to conclude that this represents a true population prevalence of
$\mathrm{OAB}$ in relation to the different $\mathrm{BMI}$ categories on the basis of the limited number of women examined, this does represent the pattern of patients' referral that most urologists see in their practices. Our study indicated that a $\mathrm{BMI} \geq 30$ was associated with a higher incidence of patient-reported urinary mixed leakage and pad use. This finding also agrees with other published data. Hannestad et al. [12] showed a positive correlation between $\mathrm{BMI}$ and incontinence, and this association has been demonstrated for all subtypes of incontinence (urge, stress, and mixed), particularly severe combined urge urinary and stress incontinence. In the Heart and Estrogen/Progestin Replacement study, Grady et al. [25] demonstrated that increasing BMI was a significant predictor of combined urge and stress incontinence. Because higher BMI was age related, one may conclude that the above observation could be related to lower activity levels in older women. Another possibility is that the increased rate of urge incontinence in older women makes stress incontinence symptoms harder to isolate, which thus makes it harder to distinguish pure urge leakage from pure stress leakage or mixed leakage.

Objectively, our UDS assessment did not show a significant correlation between $\mathrm{OAB}$ and any BMI category for most UDS parameters except for urge leakage in the comparison of groups 2 and 3. Although statistically significant, this finding between groups 2 and 3 may be purely a coincidence, because the number of subjects in each group was relatively small. This is in contrast with the subjective data based on medical history. Although the baseline $\mathrm{OAB}$ disease severity was statistically more severe in the more obese study population for some of the examined parameters, the clinical significance of this observation is unknown because it was not supported by UDS correlation.

The limitations of our study include the small number of subjects in each subset and the fact that the patient population was referral based and thus may not be a true representation of the population. In other words, the patients examined in our series were already referred for $\mathrm{OAB}$ and thus represented a biased population. Proceeding to UDS was done on the basis of the severity of the patients' symptoms and also on the basis of whether they wanted to proceed to undergo the studies. The ideal study would be to take all comers (women) regardless of symptoms and have them all complete the questionnaire and then all go on to undergo UDS. Unfortunately, this is difficult to do and not clinically relevant because we deal with patients and symptoms. Nevertheless, this study is one of the first studies to examine the association between increased $\mathrm{BMI}$ and $\mathrm{OAB}$ 
symptoms with the use of an objective tool as opposed to only establishing an epidemiologic association. Such a study should act as a base for future studies of a similar nature that are higher powered to provide a more definite answer to the role of weight loss in controlling urinary symptoms in the era of increasing obesity worldwide.

In conclusion, increasing BMI was age related. BMI $\geq 30$ appears to be associated with a higher incidence of patient-reported urinary mixed leakage and pad use. UDS assessment did not show a significant correlation with any BMI category for most UDS parameters except for urgency leakage. A larger random population series is warranted to define the relationship between $\mathrm{BMI}$ and $\mathrm{OAB}$ and UDS findings.

\section{CONFLICT OF INTEREST}

Sidney B. Radomski is advisory board member of Astellas, Pfizer, Allergan and researcher for Astellas and Allergan.

\section{REFERENCES}

1. Abrams P, Kelleher CJ, Kerr LA, Rogers RG. Overactive bladder significantly affects quality of life. Am J Manag Care 2000;6(11 Suppl): S580-90.

2. Abrams P, Cardozo L, Fall M, Griffiths D, Rosier P, Ulmsten U, et al. The standardisation of terminology of lower urinary tract function: report from the Standardisation Sub-committee of the International Continence Society. Neurourol Urodyn 2002;21:167-78.

3. Wein AJ, Rovner ES. Definition and epidemiology of overactive bladder. Urology 2002;60(5 Suppl 1):7-12.

4. Stewart WF, Van Rooyen JB, Cundiff GW, Abrams P, Herzog AR, Corey $R$, et al. Prevalence and burden of overactive bladder in the United States. World J Urol 2003;20:327-36.

5. Milsom I, Abrams P, Cardozo L, Roberts RG, Thuroff J, Wein AJ. How widespread are the symptoms of an overactive bladder and how are they managed? A population-based prevalence study. BJU Int 2001;87:760-6.

6. Hunskaar S. A systematic review of overweight and obesity as risk factors and targets for clinical intervention for urinary incontinence in women. Neurourol Urodyn 2008;27:749-57.

7. Burgio KL, Matthews KA, Engel BT. Prevalence, incidence and correlates of urinary incontinence in healthy, middle-aged women. J Urol 1991;146:1255-9.

8. Mommsen S, Foldspang A. Body mass index and adult female urinary incontinence. World J Urol 1994;12:319-22.
9. Brown JS, Seeley DG, Fong J, Black DM, Ensrud KE, Grady D. Urinary incontinence in older women: who is at risk? Study of Osteoporotic Fractures Research Group. Obstet Gynecol 1996;87(5 Pt 1): 715-21.

10. Schmidbauer J, Temml C, Schatzl G, Haidinger G, Madersbacher S. Risk factors for urinary incontinence in both sexes. Analysis of a health screening project. Eur Urol 2001;39:565-70.

11. Samsioe G, Heraib F, Lidfeldt J, Nerbrand C, Lindholm L, Agardh C, et al. Urogenital symptoms in women aged 50-59 years. Women's Health in Lund Area (WHILSA) Study Group. Gynecol Endocrinol 1999;13:113-7.

12. Hannestad YS, Rortveit G, Daltveit AK, Hunskaar S. Are smoking and other lifestyle factors associated with female urinary incontinence? The Norwegian EPINCONT Study. BJOG 2003;110:247-54.

13. Cummings JM, Rodning CB. Urinary stress incontinence among obese women: review of pathophysiology therapy. Int Urogynecol J Pelvic Floor Dysfunct 2000;11:41-4.

14. Coyne K, Margolis M, Zyczynski T, Elinoff V, Roberts RG. Validation of an $\mathrm{OAB}$ screener in a primary care patient population in the US. In: Poster presented at the ICS and IUCA 2004 Scientific Programme; 2004 Aug 25-27; Paris, France.

15. Schafer W, Abrams P, Liao L, Mattiasson A, Pesce F, Spangberg A, et al. Good urodynamic practices: uroflowmetry, filling cystometry, and pressure-flow studies. Neurourol Urodyn 2002;21:261-74.

16. Dallosso HM, McGrother CW, Matthews RJ, Donaldson MM; Leicestershire MRC Incontinence Study Group. The association of diet and other lifestyle factors with overactive bladder and stress incontinence: a longitudinal study in women. BJU Int 2003;92:6977.

17. Chancellor MB, Oefelein MG, Vasavada S. Obesity is associated with a more severe overactive bladder disease state that is effectively treated with once-daily administration of trospium chloride extended release. Neurourol Urodyn 2010;29:551-4.

18. Noblett KL, Jensen JK, Ostergard DR. The relationship of body mass index to intra-abdominal pressure as measured by multichannel cystometry. Int Urogynecol J Pelvic Floor Dysfunct 1997; 8:323-6.

19. Richter HE, Creasman JM, Myers DL, Wheeler TL, Burgio KL, Subak LL, et al. Urodynamic characterization of obese women with urinary incontinence undergoing a weight loss program: the Program to Reduce Incontinence by Diet and Exercise (PRIDE) trial. Int Urogynecol J Pelvic Floor Dysfunct 2008;19:1653-8.

20. Tyagi P, Tyagi V, Witteemer E, Kuo HC, Yoshimura N, Peters KM, et al. Expression of ghrelin receptor in bladder points to a new link between obesity and the overactive bladder. J Urol 2009;181:570. 
21. Flegal KM, Carroll MD, Ogden CL, Johnson CL. Prevalence and trends in obesity among US adults, 1999-2000. JAMA 2002;288: 1723-7.

22. Gutierrez-Fisac JL, Lopez E, Banegas JR, Graciani A, RodriguezArtalejo F. Prevalence of overweight and obesity in elderly people in Spain. Obes Res 2004;12:710-5.

23. Chapman IM. Obesity paradox during aging. Interdiscip Top Gerontol 2010;37:20-36.
24. Hughes VA, Frontera WR, Roubenoff R, Evans WJ, Singh MA. Longitudinal changes in body composition in older men and women: role of body weight change and physical activity. Am J Clin Nutr 2002;76:473-81.

25. Grady D, Brown JS, Vittinghoff E, Applegate W, Varner E, Snyder T, et al. Postmenopausal hormones and incontinence: the Heart and Estrogen/Progestin Replacement Study. Obstet Gynecol 2001;97: 116-20. 